\title{
Narrative review of current COPD status in Japan
}

\author{
Naoya Tanabe, Susumu Sato \\ Department of Respiratory Medicine, Graduate School of Medicine, Kyoto University, Sakyo-ku, Kyoto, Japan \\ Contributions: (I) Conception and design: N Tanabe; (II) Administrative support: N Tanabe; (III) Provision of study materials or patients: N Tanabe; (IV) \\ Collection and assembly of data: N Tanabe; (V) Data analysis and interpretation: Both authors; (VI) Manuscript writing: Both authors; (VII) Final \\ approval of manuscript: Both authors. \\ Correspondence to: Naoya Tanabe. Department of Respiratory Medicine, Graduate School of Medicine, Kyoto University, 54 Kawahara-cho, Shogoin, \\ Sakyo-ku, Kyoto 606-8507, Japan. Email: ntana@kuhp.kyoto-u.ac.jp.
}

\begin{abstract}
Chronic obstructive pulmonary disease (COPD) causes morbidity and mortality worldwide. Due to the improvement in environmental sanitation and medical care, the general life span has increased in the past decades in Japan. However, many older patients with COPD develop a wide range of comorbidities, and the impairments in the activities of daily living result in frailty and increase social and economic burdens. Population-based studies have shown that the prevalence of COPD is approximately $10 \%$ among subjects aged $\geq 40$ years, but more than $80 \%$ of COPD patients are underdiagnosed. The Ministry of Health, Labour, and Welfare in Japan proposed the National Health Promotion in the 21st century, termed Health Japan 21 (the second term), in 2013 to prevent the onset and progression of noncommunicable diseases (NCDs), including COPD. The government, medical society, and community have been attempting to increase the recognition of COPD and promote smoking cessation. Additionally, Japanese cohorts have revealed distinct clinical features in Japanese patients with COPD, including lower rates of patient-reported exacerbations, less frequent coexisting cardiovascular disease and metabolic syndrome, and lower use of inhaled corticosteroids in Japan compared to the Western countries. Moreover, the poor adherence to inhaled medications is found in approximately $20 \%$ of subjects, and rehabilitation is performed in $26 \%$ of hospitalized patients with COPD. Therefore, more efforts should be made to improve adherence and access to pulmonary rehabilitation. Overall, Japanese COPD patients share common clinical and social features with COPD patients in other countries. Further international corroboration may help establish better comprehensive management of the disease.
\end{abstract}

Keywords: Chronic obstructive pulmonary disease (COPD); emphysema; Japan; prevalence

Submitted Jun 20, 2020. Accepted for publication Apr 17, 2021.

doi: $10.21037 /$ jtd-20-2263

View this article at: https://dx.doi.org/10.21037/jtd-20-2263

\section{Introduction}

Chronic obstructive pulmonary disease (COPD) is a major respiratory disease that is characterized by respiratory symptoms and airflow limitation. While COPD is considered preventable and treatable, it is a leading cause of death worldwide and imposes large social and economic burdens, especially in ageing societies. Excess health-care resource utilization, increased medical costs, and loss of productivity are also social problems. Based on the current situation, this review aimed to summarize the prevalence and underdiagnosis of COPD, government policies, clinical features distinct from those of other countries, adherence to inhaler therapy, and availability of pulmonary rehabilitation in Japan. We present the following article in accordance with the Narrative Review Reporting Checklist (available at https://dx.doi.org/10.21037/jtd-20-2263). 
Table 1 Summary of the prevalence and underdiagnosis of COPD in Japan

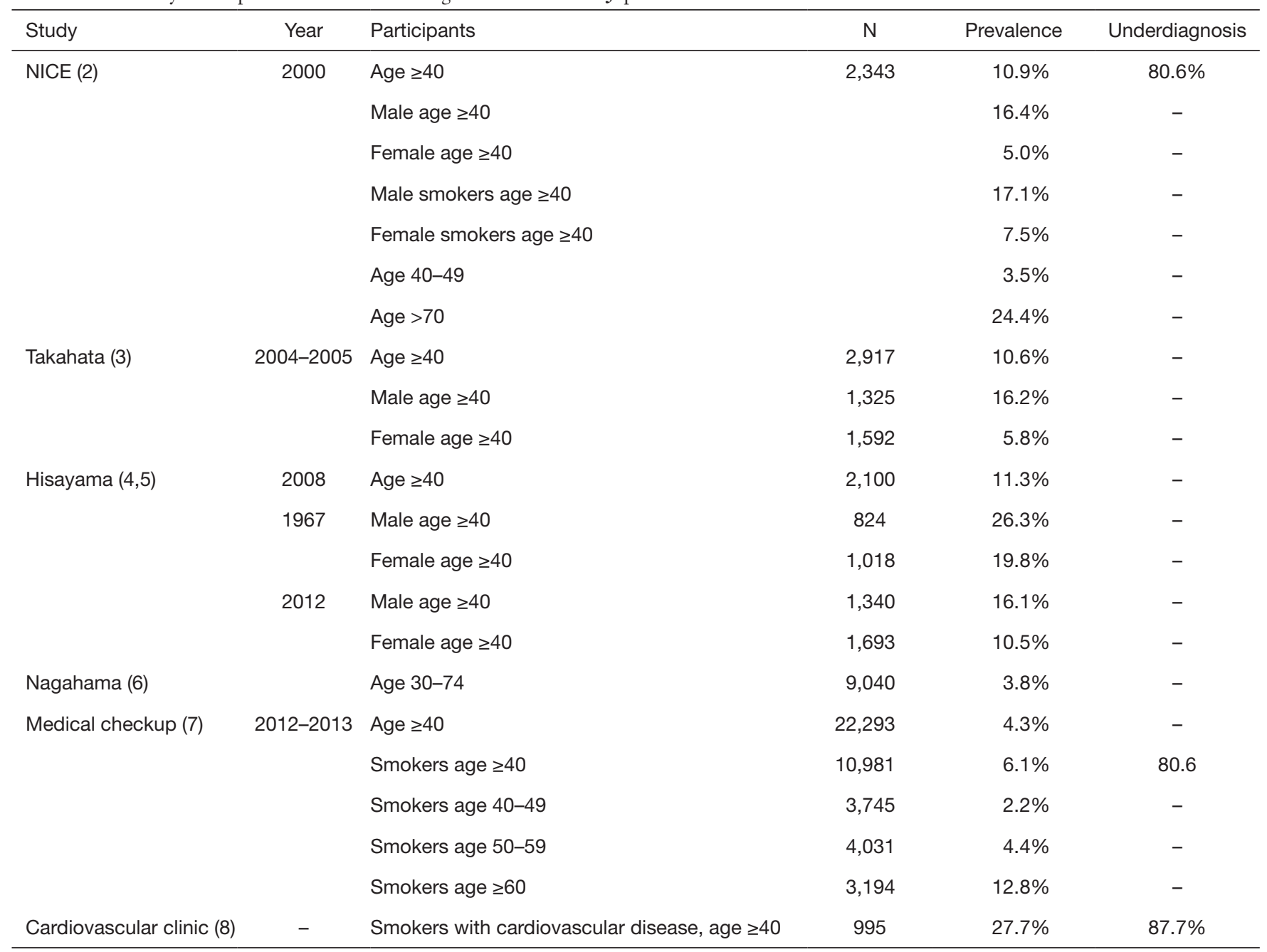

NICE (2), Takahata (3), Hisayama (4,5), and Nagahama (6) studies were conducted with a population-based approach. "Medical check-up" indicates a study that recruited subjects who underwent comprehensive medical examination, including spirometry (7). "Cardiovascular clinic" indicates a study that recruited outpatients with cardiovascular disease at primary care clinics and performed spirometry (8).

\section{Prevalence of airflow limitation and underdiagnosis of COPD}

The prevalence of airflow limitation and/or COPD is affected by multiple factors, such as region, definition of COPD, age, ethnicity, and smoking habit. A systematic review and meta-analysis showed that the global prevalence of physiologically diagnosed COPD was $9-10 \%$ among subjects aged 40 years or older (1). The prevalence of airflow limitation and the underdiagnosis of COPD according to population-based cohorts and clinic/hospital-based cohorts in Japan is summarized in Table 1 and compared to the global data in Figure 1. In 2000, a population-based study in Japan, called the Nippon COPD Epidemiology (NICE) study showed that the prevalence of airflow limitation ( $\mathrm{FEV}_{1} / \mathrm{FVC}<0.7$ without bronchodilators) in 2,343 Japanese subjects aged $\geq 40$ years was $10.9 \%$ (16.4\% among males and $5.0 \%$ among females) (2). The prevalence in former and current smokers was $15.6 \%$ and $15.4 \%$ whereas $5.8 \%$ of lifelong non-smoker showed the airflow limitation. These suggest that long-term exposure to cigarette smoke is a main cause of COPD in Japan, but other multiple factors such as abnormal lung growth, a prior history of asthma, and aging might be associated with the airflow limitation. Notably, a prior diagnosis of COPD was made in only $9.4 \%$ of those with airflow limitation. 


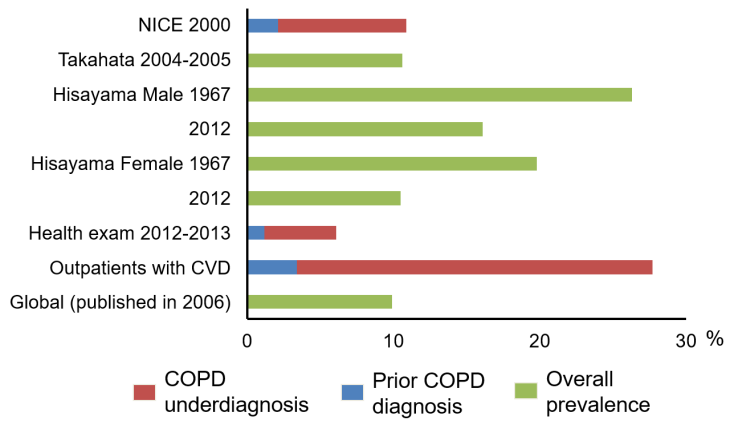

Figure 1 Prevalence and underdiagnosis of COPD in Japan. All data were based on subjects aged $\geq 40$ years. NICE (2), Takahata (3), and Hisayama (5) were conducted with a population-based approach. "Health exam" indicates a study of subjects who underwent comprehensive medical examination including spirometry (7). "Outpatients with CVD" indicates a study of outpatients with cardiovascular disease (CVD) at primary care clinics and performed spirometry (8). "Global data" indicates a meta-analysis of 34 studies including subjects aged $\geq 40$ years (1).

This finding was reproduced in other population-based studies that showed that the prevalence of airflow limitation based on $\mathrm{FEV}_{1} / \mathrm{FVC}<0.7$ without bronchodilators was $10.6 \%$ (Takahata study, n=917) and $11.3 \%$ (Hisayama study, $\mathrm{n}=2,100)$ among subjects aged 40 years or older $(3,4)$. In the population-based Nagahama study that enrolled subjects aged 30 to 74 years old, the prevalence of COPD (defined as $\mathrm{FEV}_{1} / \mathrm{FVC}<0.7$ without bronchodilators) was $3.8 \%$, which is lower than that in the studies of subjects aged 40 years or older (6). More recently, the prevalence of airflow limitation in 1967 was compared to that in 2012 using two serial population-based Hisayama cohorts (5). The prevalence decreased from $26.3 \%$ to $16.1 \%$ in men and $19.8 \%$ to $10.5 \%$ in women. Those authors suggested that the reduction in the prevalence of airflow limitation can be attributed to the improvement in environmental pollution in the atmosphere and workplace, as well as the lower smoking rate.

Studies have also shown the prevalence of airflow limitation in specific populations. In 995 patients aged $\geq 40$ years who had a smoking history of $\geq 10$ pack-years and were treated for cardiovascular disease at 17 medical centres in Japan, the prevalence of airflow limitation $\left(\mathrm{FEV}_{1} / \mathrm{FEV}_{6}<0.73\right.$ without bronchodilators) was $27 \%$, and $87.7 \%$ of those patients had not previously been diagnosed with COPD (8). Additionally, in smokers aged $\geq 40$ years who underwent comprehensive medical examinations, the prevalence of airflow limitation $\left(\mathrm{FEV}_{1} / \mathrm{FVC}<0.7\right.$ without bronchodilators) was $6.1 \%$, and $80.6 \%$ had not been previously diagnosed with COPD/emphysema (7). Moreover, a combination of the International Primary Care Airways Group (IPAG) Questionnaire and spirometry showed that the prevalence of COPD (defined as $\mathrm{FEV}_{1}$ / FVC $<0.7$ without bronchodilators) was $29 \%$ in former and current smokers aged 50 to 74 years old and $37 \%$ in those aged 75 years old or more in Ohmuta city in Japan, an area with high levels of air pollution (9). In that study, even 16\% of non-smokers aged 50 years or more showed spirometric evidence of COPD. These results suggest that while the overall prevalence of COPD in the general population aged $\geq 40$ years is approximately $10 \%$ in Japan, the prevalence may increase up to $30-40 \%$ in smokers with cardiovascular disease and those who lived in areas with high air pollution.

\section{Government policies}

Due to improvements in environmental sanitation and medical care, the life span has increased in the past decades, but during the same period, morbidity due to noncommunicable diseases (NCDs) has imposed increasing substantial social burdens. The Japanese government proposed the National Health Promotion in the $21^{\text {st }}$ century, termed "Health Japan 21 (the first term)", in 2000 to prevent the occurrence of major NCDs, including cancer, heart disease, stroke, and diabetes (10). Moreover, the Japanese government enacted the Health Promotion Law to prevent non-smokers from being exposed to cigarette smoke in public facilities in 2003 and allowed for coverage of the smoking cessation programme in the Japanese medical insurance system in 2006.

COPD was not included in the Heath Japan 21 (the first term). However, the number of subjects who died from COPD has increased continuously (Figure 2), and many older patients with COPD develop a wide spectrum of comorbidities. The impairment in activities of daily living results in frailty and has been recognized as a social problem (11). In 2013, the Ministry of Health, Labour, and Welfare in Japan revised the Health Japan 21 (the second term) and added COPD to the list of target NCDs (12). One of the goals in the Health Japan 21 is to prevent the incidence and progression of NCDs, including cancer, cardiovascular disease, diabetes mellitus, and COPD. Specifically, the government is attempting to increase the recognition of COPD from $25 \%$ of the generation population in 2011 to $80 \%$ by 2022 and to promote further 


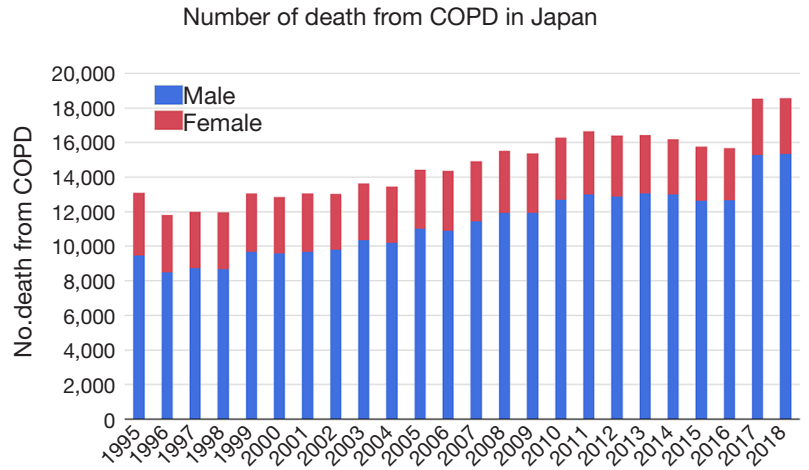

Figure 2 Trend in number of deaths from COPD in Japan. Data were obtained from the nationwide database of the Ministry of Health, Labour, and Welfare in Japan.

smoking cessation to prevent COPD. Unfortunately, the current awareness of COPD is still around 30\% (13).

\section{Distinct clinical features in Japanese COPD patients}

A diagnosis of COPD is based simply on airflow limitation that is induced by a combination of airway disease and emphysema. The relative contributions of the two structural abnormalities vary from person to person, and the clinical manifestation of the disease is substantially heterogeneous. In a nationwide survey, CT data from 1,438 patients with $\mathrm{COPD}\left(\mathrm{FEV}_{1} / \mathrm{FVC}<0.7\right.$ without bronchodilators) were evaluated. Consequently, $90 \%$ had emphysema-dominant COPD and only $10 \%$ had airwaydisease-dominant COPD (14). Meanwhile, in a multicentre study conducted across five European countries, there were 124 CT-based emphysema-dominant and 79 airway-diseasedominant phenotypes among 441 patients with COPD (15). In the COPDgene study conducted in the United States $(\mathrm{n}=4,187$ and 4,101 for training and validation datasets, respectively), cluster analysis identified an airway-diseasedominant disease phenotype in $24 \%$ of smokers and a severe emphysema-dominant phenotype in $20 \%$ of smokers (16). These suggest that the relatively lower rate of airwaydisease-dominant COPD and higher rate of emphysemadominant COPD may be a feature of Japanese COPD studies although whether this reported value actually reflects the real prevalence of airway-disease-dominant COPD is unclear.

Another distinct feature of Japanese COPD is that patient-reported exacerbation rates are lower than those in other countries (17). In the UPLIFT trial that examined the effects of tiotropium in 30 countries, including Japan, the exacerbation rate in Japanese patients ( $0.61 /$ person/year) was lower than that in patients from other Asian countries (0.92/person/year) and all countries (0.85/person/year). This difference was reflected by the 2017 GOLD ABCD classification in Japan and Spain and the United States, where groups $\mathrm{C}$ and $\mathrm{D}$ were less common in Japan than in Spain and the United States $(18,19)$. Although the definite reasons for the different rates of exacerbations in Japan and other countries remain unclear, better medical access, less frequent cardiovascular comorbidity, and better adherence to inhaled medications as described below might contribute to less frequency of exacerbations in Japan $(17,20)$. Additionally, as described in a previous review, there is the hypothesis that Japanese patients with COPD may tend to underreport their symptoms, which causes less frequency of reported exacerbations (17).

Moreover, the comorbidities of COPD are affected by multiple factors and vary among regions. In a review summarizing comorbidities in Japanese patients with COPD, cardiovascular disease and metabolic syndrome are less frequent and osteoporosis, lower body mass index (BMI), and malnutrition are more frequent in Japanese patients with COPD than in Westerners with COPD (20-22). The prevalence of osteoporosis was $18-39 \%$ and $9 \%$ in Japanese and Hungarian patients with COPD, respectively and the prevalence of diabetes was $7.8 \%$ in Japanese subjects with airflow limitation $\left(\mathrm{FEV}_{1} / \mathrm{FVC}<0.7\right.$ without bronchodilators) and $12 \%$ in Hungarian patients with COPD (20,22-24). These differences could be explained by genetic backgrounds and social and dietary behaviours. Nonetheless, we should also be aware that the prevalence of comorbidities may change in different samples. As shown in Figure 3, in observational studies conducted in a hospital, a cardiovascular disease accounts for approximately $12 \%$ of deaths in Japanese patients with COPD (diagnosed based on post-bronchodilator FEV1/FVC <0.7) $(25,26)$. In contrast, a cardiovascular disease accounted for approximately $30 \%$ of all-cause deaths in the IMPACT study conducted worldwide (28). However, in a population-based study in Takahata, of 3,253 Japanese subjects enrolled, 338 showed airflow limitation without apparent respiratory symptoms (27). Notably, 31 patients with airflow limitation died during a 7 -year follow-up, and the causes of death were respiratory failure (32\%), cardiovascular disease (29\%), lung cancer (16\%), and other organ neoplasms (13\%) (27). In terms of the annual rate of deaths related to COPD, the Takahata study suggests 


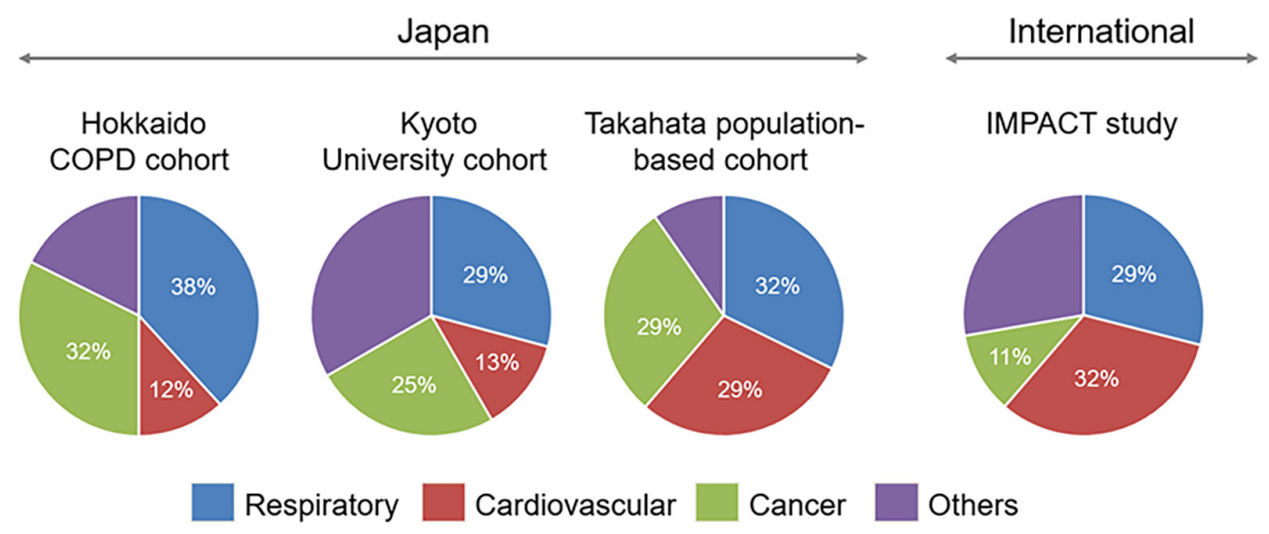

Figure 3 Causes of death in patients with COPD from Japanese and international studies. The Hokkaido COPD cohort (25) and Kyoto University cohort (26) were conducted at hospitals, and forced expiratory volume in $1 \mathrm{sec}$ (FEV1) was approximately $60 \%$ (\% predicted). The Takahata study (27) was a population-based study in which subjects with airflow limitation were included, but the severity of airflow limitation was mild (mean FEV1 was over 90\% of predicted). IMPACT (28) was an international multicentre interventional study conducted in the United States, Europe, and Asia.

that the annual rate of death in patients with COPD should be $1-2 \%$. Therefore, assuming that there are at least 6 million COPD patients in Japan, the number of annual deaths related to COPD would be approximately 60,000. However, this calculated number is more than the reported number $(18,000)$ as shown in Figure 2. This discrepancy could be because underdiagnosis of COPD might have affected the number of reported deaths associated with COPD.

\section{Asthmatic features in COPD}

Longitudinal studies have confirmed that a history of asthma including childhood asthma increases a risk of COPD (29). Moreover, COPD patients with a history of asthma have higher risk of exacerbations and respond to inhaled corticosteroid (ICS) (30). In the Kyoto-Himeji cohort which prospectively enrolled 189 Japanese patients with COPD, a history of asthma before age of 40 years was found in $28 \%$ of those with CT-defined airway disease-dominant COPD and $6 \%$ of those with CT-defined emphysema disease-dominant COPD (31). This suggests that a prior history of asthma could be associated with the development of airway diseasedominant COPD. Moreover, the Japanese Respiratory Society (JRS) proposed the diagnostic criteria of asthmaCOPD overlap (ACO) in 2018, conducted a multicentre study including 708 patients with COPD, and found that $255(36 \%)$ had a physician's diagnosis of asthma (32).
Furthermore, of 396 whose data are sufficient to evaluate the new ACO criteria, 25.5\% fulfilled the criteria of ACO (32). Meanwhile, in the Hokkaido COPD cohort $(n=268)$, $21 \%$ patients had bronchodilator reversibility, $19 \%$ had blood eosinophilia, and $25 \%$ had atopy even though patients with a history of asthma were not included (33). In the Western countries, the Subpopulations and Intermediate Outcome Measures in COPD Study (SPIROMICS) showed the percentage of COPD patients with a past history of asthma was approximately 20\% (34), and the COPD History Assessment in Spain (CHAIN) cohort including 831 patients with COPD showed that $15 \%$ met the criteria of ACO (35). Therefore, there seems to be no large difference in the prevalence of a history of asthma and/or asthmatic features in patients with COPD between Japan and other countries.

\section{Adherence to inhaled medications}

Appropriate adherence to inhaled long-acting bronchodilators and ICS is essential for the management of COPD. Poor adherence leads to the increased risk of poor clinical outcome, such as reduced quality of life and increased health-care expenditures (36). A Japanese multicentre crosssectional study analysed adherence in 479 consecutive outpatients with asthma and/or COPD who were taking both regular inhaled and oral medication (37). 
A

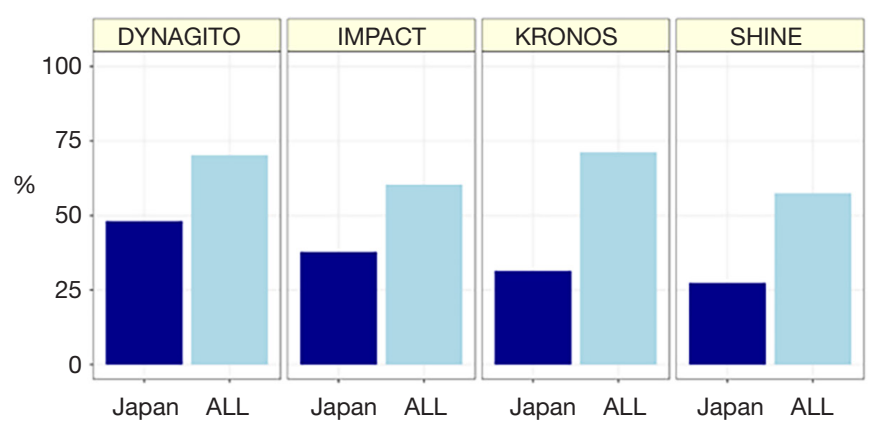

B

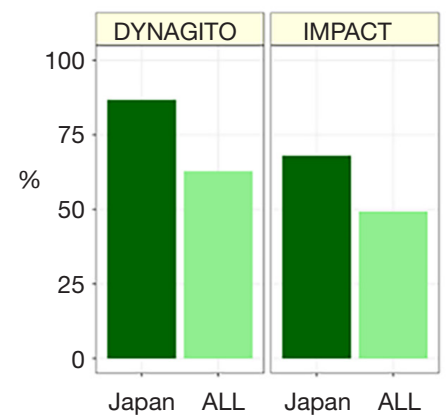

Figure 4 Use of ICSs and LAMAs prior to enrolment in international interventional studies. DYNAGITO $(41,42)$, IMACT $(43,44)$, KRONOS $(45,46)$, and SHINE $(47,48)$ studies were conducted all over the world, including in the United States, Europe, Asia, and Japan. The use of inhaled corticosteroids (ICSs) and long-acting muscarinic antagonists (LAMAs) was compared between a subset of the Japanese population and the whole data set.

Of 124 patients with COPD, $21.8 \%$ showed poor adherence to inhaled medication, and $9.7 \%$ showed poor adherence to oral medication. In another Japanese cohort, adherence to inhaled medication among COPD patients in different age groups was analysed (38). While COPD patients aged 75-84 years old ( $\mathrm{n}=115)$ had more dyspnoea, lower exercise tolerance, poorer activity of daily living, more frequent severe exacerbation, and greater cognitive decline than those aged $65-74$ years old $(\mathrm{n}=101)$, adherence to inhaled medications did not differ between the groups (good adherence rate $=82 \%$ for $65-74$ years of age and $89 \%$ for $75-84$ years of age). The percentage of patients with good adherence in Japan is higher than that in $34.7 \%$ in South Korea and $37.4 \%$ in Vietnam $(39,40)$.

The use of ICSs and long-acting muscarinic antagonists (LAMAs) to treat COPD appears to be different from that in other countries. We assessed the use of these inhalers among individuals prior to enrolment in pharmaceutical interventional studies that were conducted worldwide, including the United States, Europe, and Asia. Figure 4 compares the uses of ICS-containing (A) and LAMAcontaining (B) regimens in a subgroup analysis of Japanese COPD patients to those in the complete datasets of COPD patients worldwide (41-48). ICS use was less frequent, and LAMA use was more frequent in Japan. This might be partially influenced by the current guideline from the Japanese Respiratory Society, in which long-acting bronchodilators, but not ICS, are main therapeutic agents in COPD while ICS should be used only in patients with asthmatic features (49).

\section{Pulmonary rehabilitation}

Pulmonary rehabilitation has been shown to be effective in improving exercise capacity, health-related quality of life, physical activity, and mortality (50-52). Thus, patients with greater symptoms and lower ability to perform activities of daily living should be referred to rehabilitation programmes, and health-care workers and society need to make the rehabilitation programme more accessible and affordable. However, pulmonary rehabilitation has not been implemented as widely as pharmacological intervention. In 18,037 hospitalized patients with COPD from the Japanese Diagnosis Procedure Combination nationwide administrative claims database, only $25.5 \%$ underwent rehabilitation (50). Pulmonary rehabilitation for outpatients is significantly less frequently performed compared to rehabilitation for other non-pulmonary diseases, such as locomotive diseases. Improvement in the environment to implement pulmonary rehabilitation for outpatients is required.

\section{Long-term oxygen therapy (LTOT)}

In the COPD Assessment in Practice (CAP) study, 123 out of 1,168 Japanese patients with COPD (10\%) received LTOT (18). Another report showed that the percentage of COPD patients using home-based LTOT to all patients using home based LTOT has been approximately $50 \%$ over time (53). In a single center prospective study, of 101 COPD patients who showed mild hypoxaemia $\left(\mathrm{PaO}_{2}<80\right.$ Torr) at the baseline evaluation, $10(10 \%)$ developed 
chronic respiratory failure during 6-year follow-up and started LTOT. Diffusion capacity for carbon monoxide $\left(D_{\mathrm{LCO}}\right)$ at the baseline was associated with higher risk of future administration of LTOT in patients with COPD (54).

\section{Bronchoscopic lung volume reduction}

Bronchoscopic lung volume reduction (BLVR), particularly using endobronchial valves, has been shown to be effective in improving lung hyperinflation and exercise capacity in COPD patients (55). However, although a phase III trial had been conducted, the use of this procedure is limited in Japan. In a small report, BLVR using transbronchial infusion of autologous blood and thrombin was effective in 3 patients with very severe COPD (56). This concept needs to be further investigated in Japanese patients with advanced emphysema.

\section{Conclusion}

The prevalence rates of airflow limitation and COPD underdiagnosis are still high in Japan. Distinct clinical features such as high frequency of osteoporosis, low BMI, malnutrition, lower frequency of reported exacerbations and less frequently use of ICS in Japan should be considered when interpreting results and guidelines made based on international studies.

\section{Acknowledgments}

Funding: This work was partially supported by a grant from the Japan Society for the Promotion of Science (JSPS) [Grants-in-Aid for scientific research 19K08624].

\section{Footnote}

Provenance and Peer Review: This article was commissioned by the Guest Editor (Ki-Suck Jung and Chin Kook Rhee) for the series "current epidemiology and policies of COPD worldwide" published in Fournal of Thoracic Disease. The article has undergone external peer review.

Reporting Checklist: The authors have completed the Narrative Review Reporting Checklist. Available at https:// dx.doi.org/10.21037/jtd-20-2263

Conflicts of Interest: Both authors have completed the
ICMJE uniform disclosure form (available at https:// dx.doi.org/10.21037/jtd-20-2263). The series "current epidemiology and policies of COPD worldwide" was commissioned by the editorial office without any funding or sponsorship. Dr. Tanabe reports personal fees from AstraZeneka, personal fees from Nippon Boehringer Ingelheim, personal fees from GlaxoSmithKline, outside the submitted work. The authors have no other conflicts of interest to declare.

Ethical Statement: The authors are accountable for all aspects of the work in ensuring that questions related to the accuracy or integrity of any part of the work are appropriately investigated and resolved.

Open Access Statement: This is an Open Access article distributed in accordance with the Creative Commons Attribution-NonCommercial-NoDeri 4.0 International License (CC BY-NC-ND 4.0), which permits the noncommercial replication and distribution of the article with the strict proviso that no changes or edits are made and the original work is properly cited (including links to both the formal publication through the relevant DOI and the license). See: https://creativecommons.org/licenses/by-nc-nd/4.0/.

\section{References}

1. Halbert RJ, Natoli JL, Gano A, et al. Global burden of COPD: systematic review and meta-analysis. Eur Respir J 2006;28:523-32.

2. Fukuchi $Y$, Nishimura $M$, Ichinose $M$, et al. COPD in Japan: the Nippon COPD Epidemiology study.

Respirology 2004;9:458-65.

3. Osaka D, Shibata Y, Abe S, et al. Relationship between habit of cigarette smoking and airflow limitation in healthy Japanese individuals: the Takahata study. Intern Med 2010;49:1489-99.

4. Matsumoto K, Seki N, Fukuyama S, et al. Prevalence of asthma with airflow limitation, COPD, and COPD with variable airflow limitation in older subjects in a general Japanese population: the Hisayama Study. Respir Investig 2015;53:22-9.

5. Ogata H, Hirakawa Y, Matsumoto K, et al. Trends in the prevalence of airflow limitation in a general Japanese population: two serial cross-sectional surveys from the Hisayama Study. BMJ Open 2019;9:e023673.

6. Muro S, Tabara Y, Matsumoto H, et al. Relationship 
Among Chlamydia and Mycoplasma Pneumoniae Seropositivity, IKZF1 Genotype and Chronic Obstructive Pulmonary Disease in A General Japanese Population: The Nagahama Study. Medicine (Baltimore) 2016;95:e3371.

7. Omori H, Kaise T, Suzuki T, et al. Prevalence of airflow limitation in subjects undergoing comprehensive health examination in Japan: Survey of Chronic Obstructive pulmonary disease Patients Epidemiology in Japan. Int J Chron Obstruct Pulmon Dis 2016;11:873-80.

8. Onishi K, Yoshimoto D, Hagan GW, et al. Prevalence of airflow limitation in outpatients with cardiovascular diseases in Japan. Int J Chron Obstruct Pulmon Dis 2014;9:563-8.

9. Kotaki K, Ikeda H, Fukuda T, et al. Trends in the prevalence of COPD in elderly individuals in an airpolluted city in Japan: a cross-sectional study. Int J Chron Obstruct Pulmon Dis 2019;14:791-8.

10. Shibaike N, Utsunomiya O, Ushiro S, et al. 5. Action by Ministry of Health, Labor and Welfare National Health Promotion in the 21st century "Health Japan 21". Intern Med 2002;41:70-1.

11. Igarashi A, Fukuchi Y, Hirata K, et al. COPD uncovered: a cross-sectional study to assess the socioeconomic burden of COPD in Japan. Int J Chron Obstruct Pulmon Dis 2018;13:2629-41.

12. Ezoe S, Noda H, Akahane N, et al. Trends in Policy on the Prevention and Control of Non-Communicable Diseases in Japan. Health Syst Reform 2017;3:268-77.

13. GOLD_Japanese_Committee. Survey on the awareness of COPD [Japanese]. Available online: http://www.gold-jac. jp/. Accessed Februwary 19, 2021.

14. Tatsumi K, Kasahara Y, Kurosu K, et al. Clinical phenotypes of COPD: results of a Japanese epidemiological survey. Respirology 2004;9:331-6.

15. Subramanian DR, Gupta S, Burggraf D, et al. Emphysemaand airway-dominant COPD phenotypes defined by standardised quantitative computed tomography. Eur Respir J 2016;48:92-103.

16. Castaldi PJ, Dy J, Ross J, et al. Cluster analysis in the COPDGene study identifies subtypes of smokers with distinct patterns of airway disease and emphysema. Thorax 2014;69:415-22.

17. Ishii T, Nishimura M, Akimoto A, et al. Understanding low COPD exacerbation rates in Japan: a review and comparison with other countries. Int J Chron Obstruct Pulmon Dis 2018;13:3459-71.
18. Oishi K, Hirano T, Hamada K, et al. Characteristics of 2017 GOLD COPD group A: a multicenter crosssectional CAP study in Japan. Int J Chron Obstruct Pulmon Dis 2018;13:3901-7.

19. Cabrera López C, Casanova Macario C, Marin Trigo JM, et al. Comparison of the 2017 and 2015 Global Initiative for Chronic Obstructive Lung Disease Reports. Impact on Grouping and Outcomes. Am J Respir Crit Care Med 2018;197:463-9.

20. Takahashi S, Betsuyaku T. The chronic obstructive pulmonary disease comorbidity spectrum in Japan differs from that in western countries. Respir Investig 2015;53:259-70.

21. Ogawa E, Nakano Y, Ohara T, et al. Body mass index in male patients with COPD: correlation with low attenuation areas on CT. Thorax 2009;64:20-5.

22. Watanabe R, Tanaka T, Aita K, et al. Osteoporosis is highly prevalent in Japanese males with chronic obstructive pulmonary disease and is associated with deteriorated pulmonary function. J Bone Miner Metab 2015;33:392-400.

23. Bikov A, Horvath A, Tomisa G, et al. Changes in the Burden of Comorbidities in Patients with COPD and Asthma-COPD Overlap According to the GOLD 2017 Recommendations. Lung 2018;196:591-9.

24. Machida H, Shibata Y, Inoue S, et al. Prevalence of diabetes mellitus in individuals with airflow obstruction in a Japanese general population: The Yamagata-Takahata Study. Respir Investig 2018;56:34-9.

25. Nishimura M, Makita H, Nagai K, et al. Annual change in pulmonary function and clinical phenotype in chronic obstructive pulmonary disease. Am J Respir Crit Care Med 2012;185:44-52.

26. Tanimura K, Sato S, Fuseya Y, et al. Quantitative Assessment of Erector Spinae Muscles in Patients with Chronic Obstructive Pulmonary Disease. Novel Chest Computed Tomography-derived Index for Prognosis. Ann Am Thorac Soc 2016;13:334-41.

27. Shibata Y, Inoue S, Igarashi A, et al. A lower level of forced expiratory volume in 1 second is a risk factor for all-cause and cardiovascular mortality in a Japanese population: the Takahata study. PLoS One 2013;8:e83725.

28. Lipson DA, Crim C, Criner GJ, et al. Reduction in AllCause Mortality with Fluticasone Furoate/Umeclidinium/ Vilanterol in COPD Patients. Am J Respir Crit Care Med 2020;201:1508-16.

29. Bui DS, Lodge CJ, Burgess JA, et al. Childhood predictors 
of lung function trajectories and future COPD risk: a prospective cohort study from the first to the sixth decade of life. Lancet Respir Med 2018;6:535-44.

30. Leung JM, Sin DD. Asthma-COPD overlap syndrome: pathogenesis, clinical features, and therapeutic targets. BMJ 2017;358:j3772.

31. Tanabe N, Shimizu K, Terada K, et al. Central airway and peripheral lung structures in airway disease dominant COPD. ERJ Open Research 2021;7:00672-2020.

32. Hashimoto S, Sorimachi R, Jinnai T, et al. Asthma and Chronic Obstructive Pulmonary Disease Overlap According to the Japanese Respiratory Society Diagnostic Criteria: The Prospective, Observational ACO Japan Cohort Study. Adv Ther 2021;38:1168-84.

33. Suzuki M, Makita H, Konno S, et al. Asthma-like Features and Clinical Course of Chronic Obstructive Pulmonary Disease. An Analysis from the Hokkaido COPD Cohort Study. Am J Respir Crit Care Med 2016;194:1358-65.

34. Hastie AT, Martinez FJ, Curtis JL, et al. Association of sputum and blood eosinophil concentrations with clinical measures of COPD severity: an analysis of the SPIROMICS cohort. Lancet Respir Med 2017;5:956-67.

35. Cosio BG, Soriano JB, Lopez-Campos JL, et al. Defining the Asthma-COPD Overlap Syndrome in a COPD Cohort. Chest 2016;149:45-52.

36. Sanduzzi A, Balbo P, Candoli P, et al. COPD: adherence to therapy. Multidiscip Respir Med 2014;9:60.

37. Imamura Y, Kawayama T, Kinoshita T, et al. Poor pharmacological adherence to inhaled medicines compared with oral medicines in Japanese patients with asthma and chronic obstructive pulmonary disease. Allergol Int 2017;66:482-4.

38. Kobayashi S, Yanai M, Hanagama M, et al. Burden of chronic obstructive pulmonary disease in the elderly population. Respir Investig 2014;52:296-301.

39. Kim JA, Lim MK, Kim K, et al. Adherence to Inhaled Medications and its Effect on Healthcare Utilization and Costs Among High-Grade Chronic Obstructive Pulmonary Disease Patients. Clin Drug Investig 2018;38:333-40.

40. Nguyen TS, Nguyen TLH, Pham TTV, et al. Impact of pharmaceutical care in the improvement of medication adherence and quality of life for COPD patients in Vietnam. Respir Med 2019;153:31-7.

41. Ichinose M, Nishimura M, Akimoto M, et al. Tiotropium/ olodaterol versus tiotropium in Japanese patients with COPD: results from the DYNAGITO study. Int J Chron Obstruct Pulmon Dis 2018;13:2147-56.

42. Calverley PMA, Anzueto AR, Carter K, et al. Tiotropium and olodaterol in the prevention of chronic obstructive pulmonary disease exacerbations (DYNAGITO): a doubleblind, randomised, parallel-group, active-controlled trial. Lancet Respir Med 2018;6:337-44.

43. Kato M, Tomii K, Hashimoto K, et al. The IMPACT Study - Single Inhaler Triple Therapy (FF/UMEC/VI) Versus FF/VI And UMEC/VI In Patients With COPD: Efficacy And Safety In A Japanese Population. Int J Chron Obstruct Pulmon Dis 2019;14:2849-61.

44. Lipson DA, Barnhart F, Brealey N, et al. Once-Daily Single-Inhaler Triple versus Dual Therapy in Patients with COPD. N Engl J Med 2018;378:1671-80.

45. Ichinose M, Fukushima Y, Inoue $Y$, et al. Efficacy and Safety of Budesonide/Glycopyrrolate/Formoterol Fumarate Metered Dose Inhaler Formulated Using CoSuspension Delivery Technology in Japanese Patients with COPD: A Subgroup Analysis of the KRONOS Study. Int J Chron Obstruct Pulmon Dis 2019;14:2979-91.

46. Ferguson GT, Rabe KF, Martinez FJ, et al. Triple therapy with budesonide/glycopyrrolate/formoterol fumarate with co-suspension delivery technology versus dual therapies in chronic obstructive pulmonary disease (KRONOS): a double-blind, parallel-group, multicentre, phase 3 randomised controlled trial. Lancet Respir Med 2018;6:747-58.

47. Hashimoto S, Ikeuchi H, Murata S, et al. Efficacy and safety of indacaterol/glycopyrronium in Japanese patients with COPD: a subgroup analysis from the SHINE study. Int J Chron Obstruct Pulmon Dis 2016;11:2543-51.

48. Bateman ED, Ferguson GT, Barnes N, et al. Dual bronchodilation with QVA149 versus single bronchodilator therapy: the SHINE study. Eur Respir J 2013;42:1484-94.

49. The_Japanese_Respiratory_Society. The JRS Guildlines for the Management of Chronic Obstructive Pulmonary Disease (the 5 th edition) [Japanese]. Tokyo: Medical Review.

50. Nakahara Y, Yasunaga H, Inokuchi H, et al. MortalityReducing Effect of Rehabilitation for COPD: Observational Propensity-Matched Cohort Study Using a Nationwide Database. Respir Care 2016;61:1497-504.

51. Nici L, Donner C, Wouters E, et al. American Thoracic Society/European Respiratory Society statement on 
pulmonary rehabilitation. Am J Respir Crit Care Med 2006;173:1390-413.

52. McCarthy B, Casey D, Devane D, et al. Pulmonary rehabilitation for chronic obstructive pulmonary disease. Cochrane Database Syst Rev 2015;(2):CD003793.

53. Kida K, Motegi T, Ishii T, et al. Long-term oxygen therapy in Japan: history, present status, and current problems. Pneumonol Alergol Pol 2013;81:468-78.

54. Uemasu K, Sato S, Muro S, et al. Annual decline in arterial blood oxygen predicts development of chronic respiratory

Cite this article as: Tanabe N, Sato S. Narrative review of current COPD status in Japan. J Thorac Dis 2021;13(6):3878-3887. doi: $10.21037 /$ jtd-20-2263 failure in COPD with mild hypoxaemia: A 6-year followup study. Respirology 2019;24:262-9.

55. Sciurba FC, Ernst A, Herth FJ, et al. A randomized study of endobronchial valves for advanced emphysema. N Engl J Med 2010;363:1233-44.

56. Mizumori Y, Mochiduki Y, Nakahara Y, et al. Effects of bronchoscopic lung volume reduction using transbronchial infusion of autologous blood and thrombin in patients with severe chronic obstructive pulmonary disease. J Thorac Dis 2015;7:413-21. 